\title{
Confiança política e qualidade da democracia: um debate teórico sobre o desempenho institucional
}

\author{
Carolini Gabriel da Silva*
}

\section{Resumo}

O objetivo deste artigo é analisar se há relação entre a confiança política e a qualidade da democracia a partir do debate teórico dos modelos de desempenho institucional mobilizados pelas literaturas. Para alcançar tal objetivo, conceituamos a confiança política e os elementos que orientam o nível de apoio político expresso pelos cidadãos. Em seguida, nos dedicamos às dimensões específicas da qualidade da democracia a fim de debater o que torna o desempenho de instituições, como o Congresso Nacional e o Poder Judiciário, bom ou ruim. Ensaiamos uma aproximação teórica entre as literaturas, considerando algumas particularidades da experiência brasileira. Supomos que a relação entre a confiança política e a qualidade da democracia repousa na semelhança entre as versões do desempenho institucional que são preferíveis em um regime democrático.

Palavras-chave: Confiança política; Qualidade da democracia; Desempenho institucional; Debate teórico; Crise de desconfiança.

\section{Abstract}

The objective of this article is to analyze if there is a relation between political trust and the quality of democracy, based on the theoretical debate of the institutional performance models mobilized by literatures. To achieve this goal, we conceptualize political trust and the elements that guide the level of political support expressed by citizens. Next, we focus on the specific dimensions of the quality of democracy in order to discuss what makes the performance of institutions, such as the National Congress and the Judiciary, good or bad. We rehearsed a theoretical approximation among literatures, considering some peculiarities of the Brazilian experience. We assume that the relationship between political trust and the quality of democracy rests on the similarity between the versions of institutional performance that are preferable in a democratic regime.

Key-words: Political trust; Quality of democracy; Institutional performance; Theoretical debate; Crisis of mistrust.

\footnotetext{
* Mestranda em Ciência Política pela Universidade Federal Fluminense (UFF) e graduada em Ciência Política pela Universidade Federal do Rio de Janeiro (UNIRIO). Pesquisadora do Laboratório de Estudos Eleitorais, em Comunicação Política e Opinião Pública (DOXA-IESP/UERJ) e do Grupo de Investigação Eleitoral (GIEL/UNIRIO). E-mail: carolinicgds@gmail.com.
} 
SILVA, C. G. "Confiança política e qualidade da democracia: um debate teórico sobre o desempenho institucional"

\section{Introdução}

Uma das principais características das democracias latino-americanas contemporâneas é, em menor ou maior grau, a pouca confiança que os cidadãos atribuem às instituições. De acordo com relatórios de pesquisas realizadas em países da América Latina ${ }^{1}$, as democracias enfrentam desafios críticos, que podem ser expressos pela regularidade de altos índices de desconfiança nos partidos políticos e na classe política, e pela dificuldade em solucionar problemas ligados ao bem-estar da população (Zechmeister, Lupu e Cohen, 2017a). No Brasil, essa tendência é mais expressiva. A despeito da adesão ao regime democrático ser majoritária, os brasileiros não confiam, em diferentes graus, em parlamentos, partidos, governos e tribunais de justiça (Moisés e Carneiro, 2008). E a insatisfação com o desempenho concreto da democracia complementa o rol de orientações negativas diante do universo político (Meneguello, 2013).

A partir desses diagnósticos, várias questões estão abertas ao debate: por que a confiança nas instituições é importante? Como podemos explicar as atitudes de confiança política no Brasil? Primeiramente, argumentamos que sua importância está inscrita na teoria democrática, exatamente, no funcionamento da democracia representativa no qual foi atribuído às instituições o papel de mediadoras dos interesses dos cidadãos, na relação entre sociedade e sistema político (Moisés e Meneguello, 2013). As instituições cumprem funções fundamentais no regime democrático, do mesmo modo que regulam a distribuição do poder entre os atores políticos, garantem que o julgamento e as avaliações dos cidadãos sejam levados em conta no processo de tomada de decisões. Essas funções, além de distinguirem a democracia das outras formas de governo, conferem relevância à confiança política.

Em relação aos modelos de explicação, diferentes vertentes teóricas propõemse a analisar a variação da confiança em instituições públicas e suas possíveis causas². A abordagem alternativa mais importante, e que explicita a orientação adotada neste

\footnotetext{
${ }^{1}$ Ver Zechmeister, Lupu e Cohen (2017a; 2017b).

${ }^{2}$ Uma valiosa reflexão sobre o conceito de confiança política e seus modelos teóricos de explicação é formulada por Moisés (2005a).
} 
estudo, admite que a justificação normativa e o padrão de funcionamento das instituições são os principais elementos de explicação (Offe, 1999; Norris, 1999; Moisés, 2005a). A confiança política depende da capacidade das instituições de traduzir para os cidadãos, através de seu funcionamento prático, a sua ideia básica (Moisés, 2005a). Uma vez que sejam capazes de atuar de modo coerente com as suas normas constitutivas, o Congresso Nacional, os partidos políticos e outras instituições se tornam previsíveis, geram a expectativa de que diferentes preferências serão observadas pelo sistema político, aumentando, assim, as chances dos cidadãos de apoiá-los (Norris, 1999).

Nesses termos, a confiança é um fenômeno atrelado à experiência política, ainda que o julgamento dos cidadãos dificilmente seja elaborado fora dos contextos sociais que incluem a cultura propriamente dita. De acordo com Easton (1965) e Norris (1999), a percepção sobre o desempenho das instituições não dispensa o repertório oferecido pelos valores, pois os membros de uma comunidade nacional se identificam com as instituições à medida que aprendem a fazê-lo através da transmissão de seu significado de geração a geração. Mas são as experiências ao longo da vida adulta que capacitam os cidadãos para avaliar razoavelmente o desempenho institucional. Nesse processo, as atitudes de confiança estariam associadas com a vivência de regras que remetem, por exemplo, ao universalismo, à imparcialidade e à integridade dos procedimentos (Norris, 1999).

A interpretação do fenômeno da confiança política nos conduz ao debate acerca do desempenho das instituições nos regimes democráticos. Debate que é explorado por estudos que buscam mensurar a qualidade das democracias a partir de critérios mais expandidos e substantivos (Diamond e Morlino, 2004). Ou seja, são análises que avançam para além das perspectivas analíticas procedimentais ${ }^{3}$, na qual o atributo da qualidade depende, basicamente, da vigência de mecanismos para a seleção de elites, enquanto os cidadãos usufruem do direito, por exemplo, de escolher seus representantes através de eleições regulares e competitivas, de organização e

\footnotetext{
${ }^{3} \mathrm{O}$ trabalho de Levine e Molina (2007) pode ser considerado um exemplo desse debate em chave mais restrita.
} 
associação, e de acesso às fontes alternativas de informação. A qualidade das democracias também decorreria da maneira que as instituições cumprem os procedimentos, aplicam as leis e permanecem mobilizadas pelos valores democráticos.

A inquietude dos cientistas sociais e políticos pela qualidade das democracias abriu um amplo e rico campo de indagações que lida com desafios conceituais e operativos acerca das dimensões da vida democrática suscetíveis de avaliação. Consideramos que uma vertente da literatura sobre a qualidade das democracias, na qual as reflexões de Diamond e Morlino (2004) se inserem, contribui com preocupações a respeito das condições de aprofundamento do regime democrático. De acordo com essa vertente, a qualidade da democracia depende do desempenho das instituições no que diz respeito, por exemplo, ao primado da lei e ao controle dos atores institucionais pelos cidadãos e por outras instituições.

Isto posto, o objetivo deste artigo é analisar se há relação entre a confiança política e a qualidade da democracia a partir do debate teórico dos modelos de desempenho institucional mobilizados pelas literaturas. Para alcançar tal objetivo, na primeira seção, conceituamos a confiança política e os elementos que orientam o nível de apoio político expresso pelos cidadãos. Na segunda seção, nos dedicamos às dimensões específicas da qualidade da democracia a fim de debater o que torna o desempenho de instituições, como o Congresso Nacional e o Poder Judiciário, bom ou ruim. Por fim, ensaiamos uma aproximação teórica entre as literaturas considerando algumas particularidades da experiência brasileira. Supomos que a relação entre a confiança política e a qualidade da democracia repousa na semelhança entre as versões do desempenho institucional que são preferíveis em um regime democrático.

\section{Confiança Política}

Quase todo estudo que se debruça sobre a adesão normativa aos valores democráticos e a confiança política recorre às considerações de Easton (1965) sobre as bases de legitimidade das democracias. O autor distingue o apoio conferido pelos indivíduos ao sistema político em dois tipos ou níveis: difuso e específico. $O$ apoio 
difuso se refere às atitudes em relação ao sistema político como um todo, ou seja, no nível dos princípios e dos valores que o inspiram. Enquanto o apoio específico se refere às percepções que envolvem avaliações acerca do desempenho dos governos, das lideranças políticas e das instituições. O primeiro pode ser interpretado como uma lealdade política mais profunda, em termos de aprovação das características essenciais do funcionamento do sistema político, que resulta de um processo de socialização menos volátil às avaliações de desempenho a curto prazo, e o segundo, pelo contrário, seria uma aprovação mais efêmera em consequência da satisfação de demandas específicas.

O raciocínio que conduz Easton (1965) à subdivisão do apoio político se baseia na experiência dos cidadãos. Estes se identificam com as instituições porque aprendem a fazê-lo mediante a transferência de seu significado entre as sucessivas gerações, mas sobretudo, porque suas experiências políticas no decorrer da vida adulta, os capacitam para avaliar racionalmente seu desempenho (Moisés, 2005b). A vigência de eleições, a participação política e o aprendizado adquirido, graças aos processos institucionais que expandem ou restringem o acesso a direitos, fornecem os parâmetros de julgamento. A ideia é que, quando está organizado para garantir adequadamente a cidadania, o sistema político oferece alternativas para que todos os seus membros disputem os recursos que aspiram e que os insatisfeitos anulem sua fonte de descontentamento, ou seja, os governos insensíveis às suas demandas. Nesse contexto, crises conjunturais de apoio aos governos, aos governantes e aos partidos não se convertem, necessariamente, em crises de legitimidade do sistema político.

O fenômeno da legitimidade política, ou do apoio difuso, possui fundamentos que não podem ser buscados apenas nas flutuações do sentimento político dos cidadãos em relação aos governantes. Isso não quer dizer que essas não sejam importantes, mas mostra que as razões que justificam as crenças no sistema extrapolam o pragmatismos das flutuações. No tocante ao apoio específico, à medida que as pessoas aprendem a distingui-lo e isso se torna uma rotina, a ação de governos e de instituições são avaliadas de maneiras distintas. Essa avaliação inclui a percepção da realização da função normativa das instituições, assim como dos resultados 
SILVA, C. G. "Confiança política e qualidade da democracia: um debate teórico sobre o desempenho institucional"

viabilizados por suas ações, por exemplo, nas áreas econômicas e sociais (Moisés, 2005b).

Norris (1999) refina a análise com a introdução de novas dimensões aplicáveis à pesquisa empírica. De acordo com a autora, a discriminação dos níveis de apoio político permite explorar o fato das pessoas confiarem de modo desigual nas diferentes dimensões institucionais. Na prática, os cidadãos seriam aptos para elaborar claros julgamentos a respeito das instituições, podendo expressar apoio aos princípios e valores da democracia e, simultaneamente, criticar o desempenho dos governos representativos ou, ainda, expressar confiança nas cortes supremas enquanto rejeitam as instituições partidárias e os parlamentos. Atitudes que podem ser organizadas num continuum, que varia do apoio ao estado-nação ao apoio mais concreto aos políticos particulares, cujo pano de fundo são as gradações já desenvolvidas por Easton (1965).

O apoio político pode variar entre: apoio à comunidade, apoio aos princípios do regime democrático, apoio ao desempenho do regime, apoio às instituições democráticas e aos atores políticos (Norris, 1999). O primeiro tipo de apoio refere-se ao modo que os cidadãos se vinculam à nação, ou seja, às fronteiras territoriais e políticas que servem de base para construção de uma identidade coletiva. O segundo faz alusão à adesão dos cidadãos ao regime democrático segundo seus ideais, isto é, a adesão aos princípios como liberdade, Estado de direito, participação, etc., que opõem a democracia a outros regimes políticos. O terceiro refere-se ao desempenho quotidiano do regime democrático. O quarto tipo de apoio compreende a percepção dos cidadãos em relação ao desempenho das instituições, como os partidos políticos, o parlamento e o judiciário. Por fim, o último nível diz respeito ao apoio à classe política.

Retomando as ideias de Easton (1965), a autora e seus colaboradores concluem que as atitudes geradas pela experiência institucional dos cidadãos estão relacionadas com as regras que regulam o jogo político, cujo resultado é a relação entre ganhadores e perdedores. Em outros termos, as experiências de sucesso e derrota de políticos, partidos e grupos de interesse para cargos executivo, legislativo e judiciário influenciam as atitudes dos cidadãos. As pessoas são mais propensas a apoiar as instituições se as regras que regulam a competição política asseguram a possibilidade 
de vitória para seu partido ou candidato de interesse. Norris (1999) ressalta que os eleitores que apoiam o partido ganhador expressam significativamente mais confiança nas instituições do que aqueles que apoiam os partidos perdedores. Ademais, o apoio institucional também tende a ser maior em estados caracterizados por uma ampla gama de direitos políticos e liberdades civis, sugerindo uma associação entre a desconfiança nas instituições democráticas e o mau funcionamento das regras institucionais (Norris, 1999).

Um contexto de permanente derrota do partido político de preferência dos cidadãos ou o constante desprezo das demandas por parte dos governos, parlamentos e tribunais indicam pouco ou nenhum poder de influência sobre o processo decisório. E as consequências mais palpáveis seriam frustração, desconfiança e a crítica das instituições (Moisés, 2005b; Norris, 1999). Em suma, os estudos sublinham a influência da experiência dos cidadãos sobre a confiança política, isto é, como a vivência de normas, regras e procedimentos inspiram atitudes em relação ao sistema político. E mais do que isso, mostram que a qualificação das instituições depende do aprendizado gerado pelo seu próprio funcionamento, que em tese deve promover o aproveitamento amplo das oportunidades da democracia.

Nesse esquema conceitual dois elementos-chave orientam a confiança política: a justificação normativa e a performance institucional. No primeiro caso, estamos falando das regras e normas que conduzem à criação das instituições e que posteriormente servem de parâmetro para seu funcionamento. As regras constitutivas se definem no ambiente discursivo da sociedade e resultam da disputa dos atores pelo sentido da política, por isso são referências tanto da ação dos responsáveis pela condução das instituições quanto do cidadão comum (Moisés, 2005b). Exemplificando, as agremiações partidárias existem para representar os interesses dos cidadãos, apresentar programas e ideologias, e, uma vez no poder, aplicá-los; o Congresso Nacional, para elaborar leis e controlar o Executivo; a polícia, para a manutenção da segurança pública. O fato é que as instituições não seriam neutras, mas mecanismos de mediação política instruídos por valores que, por sua vez, resultam das escolhas 
SILVA, C. G. "Confiança política e qualidade da democracia: um debate teórico sobre o desempenho institucional"

que os cidadãos fazem para enfrentar seus desafios políticos (Offe, 1999; Warren, 1999).

O segundo elemento é decisivo para a confiabilidade, pois envolve a avaliação sobre o desempenho institucional. Nessa dimensão, espera-se que as instituições adotem decisões estratégicas que recorram com frequência ao seu programa fundador. A inversão das normas e dos valores na práxis - os partidos não representam, o Congresso não legisla e nem exerce o devido checks and balances, e a polícia é inerte - produz necessariamente uma incoerência entre a justificação normativa e a performance institucional que afeta a disposição para confiar. Se torna inteligível que confiar nas instituições é aceitar como válidos suas regras constitutivas, sua missão e por consequência os valores que as animam, mas também é ter uma percepção razoavelmente positiva sobre seu desempenho.

Qualquer análise que tenha enquanto objeto o desempenho institucional deve especificar seus critérios de avaliação a fim de demonstrar o que o torna bom ou ruim. Neste caso, há uma orientação de que no julgamento feito pelos cidadãos é a justificação normativa que fornece os parâmetros de avaliação. As regras constitutivas das instituições, principalmente, aquelas relativas à sua justificação, produzem expectativas sociais e políticas a respeito do seu desempenho diário. Nessas condições, os julgamentos dos cidadãos para decidir confiar nas instituições referem-se à performance destas e, ao mesmo tempo, se baseiam na coerência interna de suas normas (Moisés, 2005a). É plausível que o ordenamento normativo atribua sentido à vida política e constitua assim uma referência para os cidadãos. Portanto, a confiança política não contrapõe os princípios normativos à racionalidade dos indivíduos no processo de avaliação da performance institucional, pelo contrário, assume um nível de conformidade entre eles.

Até agora tratamos as regras constitutivas em sentido abstrato, mas alguns autores avançam ao definirem quais valores importam na avaliação das instituições políticas. Moisés e Carneiro (2008), por exemplo, concluem que as experiências dos cidadãos brasileiros influenciam as atitudes de confiança e estão associadas com a vivência de normas, regras e procedimentos que remetem ao princípio da igualdade de 
todos perante a lei. As instituições conquistam a confiança dos cidadãos à medida que seu desempenho é capaz de revelar o universalismo, a imparcialidade, a justeza e a probidade de seus procedimentos (Moisés e Carneiro, 2008). Valores semelhantes àqueles ressaltados por Offe (1999) - justiça, imparcialidade, neutralidade, igualdade perante a lei e participação política igualitária - e que guardam afinidade com a tese de Norris (1999) sobre a importância da existência de arranjos institucionais que sejam de fato "reservatório de boa vontade pública".

Em contraste, o distanciamento dos cidadãos das instituições democráticas e a desconfiança política corresponderiam às situações em que os cidadãos se sentem desrespeitados por procedimentos institucionais ilícitos ou não autorizados, a exemplo de eleições irregulares ou fraudulentas, corrupção e comportamentos antirrepublicanos de governos e políticos; ou, ainda, quando os cidadãos não acreditam que as instituições funcionam de acordo com o fim para qual existem; e, finalmente, quando se convencem de que alguns têm mais acesso a direitos civis, políticos e sociais do que outros - ao contrário do que afirmam as leis do país (Moisés, 2005a).

Nessa reflexão, está implícita a coincidência entre os valores fundadores do regime democrático e a missão das principais instituições políticas, como os partidos, o Congresso Nacional e o Poder Judiciário. É esperado que encontremos valores como igualdade, justiça em termos de procedimentos, transparência, bem público, entre outros como critérios em destaque no julgamento dos cidadãos sobre a performance institucional, tendo em vista que a existência das instituições se fundamenta na própria essência do regime democrático. Não desconsideramos o fato de que valores com sentido ético negativo acrescidos pelo auto interesse pautem parâmetros de avaliação do desempenho institucional e consequentemente possam orientar as ações estratégicas de instituições, afinal de contas a missão destas se define na esfera discursiva da sociedade e depende da interpretação dos cidadãos. Mas se trata de dar centralidade ao fato de o regime democrático atribuir missões específicas às instituições. Este ponto será explorado na próxima seção, a partir do debate de três dimensões da qualidade das democracias diretamente relacionadas com 0 
desempenho das instituições políticas. Supomos que a relação entre a confiança política e a qualidade das democracias repousa na coerência entre as versões do desempenho institucional mobilizadas pelas literaturas.

\section{Dimensões da qualidade da democracia}

Uma análise da qualidade das democracias pode ser considerada uma tentativa de mensurar o quão democráticas são as democracias em questão ou o que as fazem boas ou ruins. Essa tarefa requer um consenso por parte dos pesquisadores acerca das dimensões do regime democrático passíveis de avaliação. Diamond e Morlino (2004) apresentam oito dimensões em que a qualidade das democracias pode variar. Cinco delas são procedimentais: Estado de direito, participação política, competição política e accountability horizontal e vertical. Duas dimensões dizem respeito às questões substantivas ou de conteúdo: o respeito às liberdades civis e políticas, e a implementação da igualdade legal, política e socioeconômica. E, por fim, a dimensão dos resultados refere-se à responsiveness, enfocando nos outputs oferecidos pelo sistema político na forma de políticas públicas e leis, e como estas refletem os interesses dos cidadãos. Nossa discussão se concentrará nas dimensões Estado de direito, accountability vertical e accountability horizontal, pois estas revelam o papel de instituições específicas, como o Congresso Nacional e o Poder Judiciário.

A ideia de Estado de direito ou rule of law remete a um contexto no qual todos os cidadãos são iguais perante a lei, e esta é universal, pública e aplicada por um Judiciário independente. Tal dimensão é amplamente discutida por O’Donnel (2004) no intuito de apontar que um estado democrático de direito não remete apenas à organização do Poder Judiciário, mas sim aos princípios que regem o sistema e o transformam, de fato, em democrático. Sendo assim, o sistema legal deve: 1) garantir os direitos políticos, civis e o conjunto de garantias de um regime democrático; e 2) estabelecer os mecanismos de controle e fiscalização, de modo que as leis sejam aplicadas até às autoridades mais altas da república. 
Para o funcionamento desse quadro legal, além da importância dos mecanismos de controle sobre a atuação das autoridades (que também serão debatidos ao longo da seção), a efetividade do sistema legal se torna imperativa (O’Donnell, 2004). O nível de inclusão do sistema legal não pode ser limitado pela existência de leis e critérios judiciais que discriminam de acordo com raça, gênero, etnia ou qualquer outro atributo. Práticas discriminatórias conduzem às falhas sistemáticas nas relações entre o Estado e grupos específicos, que se materializam em formas de tratamento diferenciadas dos agentes públicos em relação aos cidadãos "comuns" e consequentemente no acesso mais restrito destes às instituições que lidam diretamente com questões públicas e de direito. Na América Latina, por exemplo, a forma como os cidadãos considerados subalternos são tratados os tornam dependentes de um favor e não sujeitos detentores de direitos previstos constitucionalmente (O'Donnell, 2004).

A capacidade de abrangência do sistema legal também pode se tornar problemática pela ausência do Estado em certas regiões do país. As ditas "brown areas" remetem justamente à existência de espaços nacionais integrados do ponto de vista político e econômico, onde, no entanto, o aparato legal do Estado não tem vigência efetiva (O’DONNELL, 2004). Isso implica, o contínuo exercício de negociação entre legalidades formais e informais, sobretudo no quesito segurança pública. À título de exemplo, algumas áreas periféricas das cidades brasileiras experimentam investidas das forças estatais que tentam retomar o controle de áreas comandadas por contraventores. Neste caso os direitos de participação política e de voto não são problemáticos, exceto raramente. Já no que tange ao acesso aos direitos civis, este é limitado.

Os desafios acerca do funcionamento do Estado de direito não se resumem aos postos acima. Um olhar mais apurado sobre seus problemas de implementação nos leva a uma das reflexões fundamentais desse trabalho que versa sobre a relação do Poder Judiciário com as outras instituições auxiliares. O Judiciário, por um lado, deve ser livre das influências do Executivo, do Legislativo e de qualquer outro interesse privado, sendo eficiente e universalista na aplicação das leis. E por outro, não deve 
abusar de sua autonomia promovendo benefícios setoriais e interpretações não democráticas ou arbitrárias de leis. Dessa forma, é razoável afirmar que a significativa independência do Judiciário em relação às influências políticas e a ausência de corrupção nos aparatos políticos, administrativos e judiciais são maneiras de aferir o quanto o rule of law é preservado e respeitado pelas diferentes democracias (Morlino, 2004).

Nesse sentido, Diamond (2007) afirma que o controle da corrupção requer instituições específicas para examinar a conduta de funcionários públicos e investigar sinais de malversação de recursos públicos. Não há como controlar a corrupção sem despender recursos para o fortalecimento de instituições. A precisão legal das decisões deve ser abrangente para ser eficaz, isso requer recursos para deter a tentação de decisões parciais e para estabelecer um alto espírito corporativo (Diamond, 2007). Se evidências confiáveis de irregularidades surgirem, o meio institucional se consistente é capaz de julgar o infrator suspeito e impor punição ao culpado. Entretanto, a falha mais incapacitante nos sistemas de controle de corrupção é a inabilidade de aplicar esta função livre de interferências pelos mais altos níveis de governo.

As influências políticas sobre o Poder Judiciário despertam a atenção no que tange a persistente e difusa tentação de políticos em utilizar as leis - o que não se resume as leis eleitorais - contra adversários políticos (MORLINO, 2004) em situações caracterizadas por insatisfação com derrotas eleitorais ou por disputas em torno de políticas relevantes que representam modificações no status quo. Políticos são tentados a usar recursos judiciais para reforçar suas posições, e quando dispõem do apoio de juízes e da mídia atuam na retaliação de certas políticas e de personalidades influentes. Podemos concordar com Morlino (2004) no ponto de vista de que há no imaginário popular e da classe empreendedora a ideia de que a lei muitas vezes impede a realização de seus próprios interesses, mas acrescentamos que, em especial, na disputa entre forças políticas opostas na câmara baixa brasileira, que recentemente dominam as atenções de analistas, a instrumentalização das leis é o recurso utilizado na consecução de interesses particulares. 
Em suma, a dimensão rule of law é a base fundamental a partir da qual todas as outras dimensões se estabelecem e atingem níveis diferenciados de qualidade democrática, e sua análise em qualquer democracia requer cautela a fim de identificar quais são os fatores que impedem sua completa realização. A argumentação de Diamond e Morlino (2004) vai na direção de que o sistema legal ideal é favorável a democratização uma vez que atua na preservação dos direitos civis e políticos dos cidadãos e reforça os mecanismos horizontais de fiscalização da legalidade das ações daqueles que ocupam os postos do governo. Reconhecemos que vários aspectos dos tópicos sugeridos existem em poucos países, e são condições difíceis de serem criadas seja pela ausência de uma tradição burocrática, seja pela falta de vontade política. Desta forma, podemos optar por uma abordagem mais razoável que leve em consideração avanços, mesmo que limitados, em direção a essa condição ideal.

A accountability remete à obrigação dos políticos eleitos de prestar contas de suas ações quando indagados por eleitores ou por outros atores institucionais. Diamond e Morlino (2004), seguindo os argumentos de Schedler (1999), sugerem que a accountability possui três características principais: informação, justificação e punição/compensação. Em relação à primeira característica, podemos considerar que dispor de informações sobre a atuação de políticos ou sobre as decisões de instituições, como os partidos políticos e o Congresso Nacional, é condição indispensável para atribuir responsabilidades. A justificação, por sua vez, refere-se às razões fornecidas pelos governantes e pelo corpo político a fim de justificar as decisões tomadas. E a última, punição ou compensação, são as consequências resultantes da avaliação de eleitores ou autoridades sobre as informações e as justificativas de um determinado ato político. Dessa forma, a consecução da accountability requer uma esfera pública minimamente plural, que seja composta por cidadãos independentes, informados e, em certa medida, participativos.

A accountability pode ser vertical ou horizontal. Através da accountability vertical os cidadãos demandam explicações acerca dos atos praticados pelos governantes. Esse tipo de accountability tem uma natureza temporal e depende da ocorrência de eleições razoavelmente justas e competitivas, através das quais os 
cidadãos podem punir ou premiar um representante votando contra ele ou a seu favor com base em seu desempenho ao longo do mandato. Claramente, o que pode ser definido como principal canal de accountability vertical são as eleições, que ocorrem de tempos em tempos ${ }^{4}$. No entanto, é discutível o nível de efetividade delas enquanto mecanismo de accountability, tendo em vista a dinâmica por trás da disputa pelo poder que em muitas democracias envolve reversões políticas repentinas, criação de novas legendas, temas de políticas públicas pouco definidos e alta volatilidade de eleitores e partidos (O'DONNELL, 1998). Assim como O'Donnell (1998), consideramos que não apenas as eleições, mas também as reinvindicações sociais proferidas individualmente ou por alguma organização com referência àqueles que ocupam cargos nas instituições do Estado são dimensões da accountability vertical.

O impacto de reinvindicações, especialmente, daquelas que exigem destituição ou punição de autoridades públicas por atos ilícitos ou que se referem às preferências da opinião pública acerca de decisões importantes, pode, se abundante o suficiente, obstruir determinadas políticas e levar à derrota de governantes em pleitos eleitorais. Mas as consequências efetivas de tais reivindicações, principalmente de primeiro tipo, dependem muito das ações de autoridades e de agências estatais encarregadas de investigar, obstruir procedimentos e punir delitos. Desse modo, a existência de liberdades de expressão e reunião, de eleições competitivas e justas e de acesso a variadas fontes de informação não esgotam os requisitos da accountability vertical, uma accountability horizontal fraca ou irregular pode diminuir significativamente sua eficácia. É importante ressaltar que a generalização de um sentimento de insatisfação ou reprovação entre a opinião pública não deve incorrer na substituição dos "tribunais".

Na sua dimensão horizontal, a accountability refere-se à responsabilização das autoridades públicas por outros atores institucionais que possuem o poder de revisão das ações e de punição dos governantes. Como exemplos de instituições que integram

\footnotetext{
${ }^{4}$ Para além do voto, uma forma típica de participação popular mais conhecida e mobilizadora, o controle vertical institucionalizado pode ser exercido por meio de instrumentos, como o plebiscito, o referendo e a iniciativa popular. Entretanto, são instrumentos que conotam pouca força social em razão do pouco uso na história brasileira.
} 
esse sistema podemos apontar as cortes supremas, comissões especiais de inquérito formadas pelo Legislativo e as agências de auditoria. Podemos nos referir também às atividades diárias de controle do governo exercida pela oposição no Congresso Nacional. A qualidade da accountability horizontal dependeria da existência de um sistema legal que reforce a importância de checks and balances, no qual as autoridades atuem de forma independente do governo e não se apresentem enquanto alternativa política na competição eleitoral (Diamond e Morlino, 2004). A instrumentalização de instâncias de controle horizontal para fins particulares levaria a relativização da capacidade das instituições de manter as regras do jogo democrático.

Esta seção teve o objetivo de explorar o consenso identificado nas formulações de Diamond e Morlino (2004) acerca do desempenho das instituições políticas. Ressaltamos as versões do desempenho institucional que são desejadas nas democracias, principalmente àquelas que se referem ao Congresso Nacional e ao Poder Judiciário. Na próxima seção, ensaiamos uma aproximação teórica entre a confiança política e a qualidade da democracia a partir dos critérios de avaliação do desempenho institucional propostos pelas literaturas, sem desconsiderar outras aproximações já aplicadas por estudos recentes.

\section{Aproximações entre duas agendas}

As dificuldades que o Brasil enfrenta, presentemente, de solidificação das suas instituições políticas como mediadoras entre Estado e sociedade propiciam algumas reflexões sobre o processo de construção democrática. De maneira geral, essas reflexões não sinalizam o risco de retrocessos institucionais e de rupturas bruscas do regime político. Elas ressaltam a institucionalização de atitudes de desconfiança e o distanciamento dos cidadãos da arena política (Moisés, 2008; Moisés e Meneguello, 2013). A preocupação de boa parte da literatura está voltada às consequências da desconfiança para a qualidade das democracias. Baquero (2003), por exemplo, reconhece que as atitudes de desconfiança política não constituem novidade e sua 
presença na sociedade brasileira remete a um legado que afeta a qualidade da democracia do país.

Nas últimas décadas o Brasil, assim como outros países da América Latina, empreendeu um processo de restauração democrática com avanços significativos, principalmente, na dimensão institucional. Um sistema de representação com participação livre e universal da população adulta e um quadro de igualdade de direitos e de regras do jogo foram instaurados. O sistema político passou a cumprir com os requisitos poliárquicos elementares de uma democracia. Todavia a expectativa de geração e manutenção de uma relação mais madura, estável e eficiente com as instituições não tem se materializado. As atitudes negativas dos cidadãos em relação às instituições-chave - em maior medida os partidos políticos e em menor medida o Poder Judiciário - parecem colocar essa jovem democracia em estado de estagnação, no que diz respeito ao aperfeiçoamento da representação e da participação política. Pode-se dizer que o caminho da democratização tem se mostrado mais difícil do que se previa quando o país se intitulou formalmente democrático.

A desconfiança é um elemento que influencia as relações dos cidadãos com o sistema político e suas consequências assumem características particulares nas novas democracias. Os cidadãos que protagonizam a síndrome da desconfiança institucional, embora expressem adesão ao significado normativo do regime democrático, tenderam, muitas vezes, a afastar-se da política, desinteressar-se de seus rumos e demonstrar preferência por modelos de democracia que excluem partidos políticos e parlamentos (Moisés e Carneiro, 2008; Moisés e Meneguello, 2013). O que é problemático, pois o processo de democratização exige mais do que sua valorização normativa, ou seja, o apreço por seus princípios e valores. O envolvimento com as instituições e o acompanhamento - através da mídia, de partidos e de associações da sociedade civil - do desempenho de governos e do poder público são práticas que incrementam a qualidade democrática (Moisés, 2010b). Dessa forma, o excesso de desconfiança nas instituições políticas não caracterizaria as condições ideais de engajamento cívico e, muito menos, uma atitude favorável ao aprofundamento da democracia. 
A partir desses argumentos é possível identificar uma aproximação entre o fenômeno da confiança política e a noção de qualidade da democracia: o fato de os cidadãos confiarem ou não nas suas instituições condicionaria o aprofundamento do regime democrático. De acordo com esse raciocínio, a corrosão do apoio político específico desaceleraria o processo de democratização, ou seja, a transformação da democracia em um regime pleno no que diz respeito ao aperfeiçoamento das suas instâncias de accountability, participação e responsiveness (Diamond, 2002; O'Donnel, 1991). Mesmo sendo relevante, principalmente no caso das novas democracias, tal aproximação não esgota outros ângulos de análise. Toda a discussão sobre a confiança política estabelece direta ou indiretamente como parâmetros normativo e avaliativo do desempenho institucional dimensões segundo as quais a qualidade da democracia pode variar. De forma mais específica, o universalismo, a imparcialidade, a integridade e a responsividade são alguns dos aspectos mobilizados pela literatura sobre o apoio político, para aferir a qualidade do desempenho institucional, que estimulam os laços de solidariedade e confiança entre os cidadãos e as instituições. A aproximação entre as duas agendas repousa no fato da confiança política e da qualidade da democracia estarem atreladas ao cumprimento por parte das instituições de condições objetivas, como a primazia do Estado de direito e da rede de accountabilities. Em termos teóricos, o apoio às instituições políticas dependeria da qualidade da ação institucional.

\section{Considerações finais}

Neste trabalho, o esforço analítico se concentrou na relação entre a qualidade da democracia e a confiança política. Identificamos que tal relação de fato existe e pode ser explorada a partir de dois pontos de vista. O primeiro, que já é adotado por muitos estudos, compreende que a manutenção de altos níveis de desconfiança nas instituições políticas constitui um entrave ao aperfeiçoamento das democracias ao afastar os cidadãos da arena política (Moisés, 2008; Moisés e Meneguello, 2013). E o segundo, mais complexo a nosso ver, sinaliza que a confiança política e a qualidade da democracia estariam relacionadas pelos critérios que mobilizam para aferir o 
desempenho institucional, ou seja, as literaturas promovem um debate acerca do funcionamento das instituições a partir de critérios semelhantes, como a aplicação do Estado de direito e dos controles verticais e horizontais dos atores institucionais. Essa descoberta revela que a qualidade do funcionamento das instituições políticas tem muito a dizer não apenas sobre as condições em que as democracias se encontram, mas também sobre a crise de desconfiança que assola o Brasil nos últimos anos.

Para futuras pesquisas que se dedicarem à analise empírica dessa relação, a observação da evolução política do país e dos problemas inerentes a ela é obrigatória. À título de exemplo, se nos concentramos entre 2006 e 2016 podemos verificar diferenças qualitativas entre o desempenho do Poder Judiciário e o das instituições representativas. Importantes condenações de atores políticos e aberturas de investigações contra membros dos principais partidos, entre eles PT, MDB e PSDB foram levadas a cabo. O aperfeiçoamento da accountability horizontal e o grau de aplicação do rule of law foram acompanhados pela mudança de perfil do Judiciário e pela inauguração de procedimentos institucionais que se revelaram fundamentais para a efetividade de investigações. Certamente, o endurecimento penal dos crimes políticos, com a condenação em regime fechado de atores institucionais de destaque nacional, aumentou o custo de ser corrupto no Brasil, seja para a elite política, seja para a elite empresarial.

No mesmo período, ocorreram diversas denúncias de corrupção cuja repercussão envolveu diferentes instituições - principalmente os partidos políticos e o Congresso Nacional - que, em tese, podem assegurar maior controle sobre as decisões que mobilizam grandes somas de recursos públicos. A nível federal, vem à mente de forma emblemática o escândalo do "mensalão". Um esquema de compra de votos de parlamentares que quase resultou em um processo de impeachment do presidente Lula e, consequentemente, numa crise profunda da democracia.

O caso Petrobras, revelado pela Operação Lava Jato ${ }^{5}$, da Polícia Federal, também está entre os principais escândalos da política brasileira desde a

\footnotetext{
${ }^{5}$ Operação da Polícia Federal do Brasil, deflagrada em março de 2014, que investiga um esquema de lavagem e desvio de dinheiro envolvendo a Petrobras, grandes empreiteiras do país e políticos.
} 
redemocratização. Com ele, alguns fatos sobre a corrupção no Brasil se tornaram evidentes. O mais relevante deles é o comprometimento de políticos com práticas de financiamento ilegal de campanha feito com recursos públicos conseguidos em empresas estatais mediante a intermediação de empreiteiras. Esquemas, que sob uma perspectiva agregada, orientam a atuação de partidos com representação significativa tanto na Câmara dos Deputados quanto no Senado.

A conjuntura política tem muito a dizer sobre os impasses que afetam a performance das instituições. Podemos considerar que as práticas antirrepublicanas, ao atravessarem as organizações partidárias e o parlamento, constituem entraves ao controle horizontal e vertical dos atores institucionais, assim como tornam a aplicação de leis e procedimentos mais volatíl aos sabores e dissabores do poder. Os estudos sobre a desconfiança política no Brasil e em outros países da América Latina precisam promover análises aprofundadas do desempenho institucional que levem em consideração a cultura política, as características do sistema político e as correlações de forças que aumentam ou diminuem a coerência entre a justificação normativa das instituições e o modo concreto que elas atuam.

\section{Referências bibliográficas}

BAQUERO, M. 2003. "Construindo uma outra sociedade: o capital social na estruturação de uma cultura política participativa no Brasil". Revista de Sociologia e Política, Curitiba, n. 21, pp. 83-108, novembro.

Disponível em: http://www.scielo.br/scielo.php?script=sci arttext\&pid=S010444782003000200007\&lng=en\& nrm=iso. Acesso em: 31 jul. 2017.

. 2001. "Cultura política participativa e desconsolidação democrática: reflexões sobre o Brasil contemporâneo". São Paulo Perspectiva, São Paulo, v. 15, n. 4, pp. 98-104, dezembro. Disponível em: http://www.scielo.br/scielo.php?script=sci arttext\&pid=S010288392001000400011\&lng=en\&nrm=iso. Acesso em: 22 out. 2017.

BAQUERO, M.; LINHARES, B. de F. 2011. "Por que os brasileiros não confiam nos partidos? Bases para compreender a cultura política (anti) partidária e possíveis saídas". Revista Debates, Porto Alegre, v. 5, n. 1, pp. 89-114. 
BAQUERO, M.; GONZALEZ, R. S. 2016. “Cultura política, mudanças econômicas e democracia inercial. Uma análise pós-eleições de 2014". Opinião Pública, Campinas, v. 22, n.3, pp. 492523, Dezembro.

Disponível em: http://www.scielo.br/scielo.php?script=sci arttext\&pid=S010462762016000300492\&lng=en\&nrm=iso. Acesso em: 24 nov. 2017.

COLEN, C. M. L. 2010. "As covariantes da confiança política na América Latina". Opinião Pública, Campinas, v. 16, n. 1, pp. 1-27, junho. Disponível em: http://www.scielo.br/scielo.php?script=sci arttext\&pid=S010462762010000100001\&lng=en\&nrm=iso. Acesso em: 28 out. 2017.

DIAMOND, L. 2007. "Building Trust in Government by Improving Governance". Paper Presented to the 7th Global Forum on Reinventing Government: Sponsored by the United Nations Session V: Elections, Parliament, and Citizen Trust. Vienna, June 27.

DIAMOND, L.; MORLINO, L. (eds.). 2005. Assessing the Quality of Democracy. Baltimore: The Johns Hopkins University Press.

2004. "The Quality of Democracy: An Overview". Journal of Democracy, Washington, v. 15, n. 4, pp. 20-31.

EASTON, D. 1965. A system analysis of political life. Nova York: Wiley.

FILGUEIRAS, F. 2013. "Perceptions on justice, the judiciary and democracy". Brazilian Political Science Review, São Paulo, v. 7, n.2, p. 62-87. Disponível em: http://www.scielo.br/scielo.php?script=sci arttext\&pid=S198138212013000200003\&lng=en\&nrm=iso. Acesso em: 28 jan. 2019.

FUKS, M. et al. 2016. "Qualificando a adesão à democracia: quão democráticos são os democratas brasileiros?" Revista Brasileira de Ciência Política, n. 19, pp. 199-219.

GUNTHER, R.; MONTEIRO, J. R. 2003. "Legitimidade política em novas democracias". Opinião $\begin{array}{lllll}\text { Pública, Campinas, v. } & 9, \mathrm{n} . & 1, \mathrm{pp} . & 1-43 . & \text { Disponível em: }\end{array}$ http://www.scielo.br/scielo.php?script=sci arttext\&pid=S010462762003000100001\&lng=en\&nrm=iso. Acesso em: 25 out. 2017.

HAGOPIAN, F. 2005. "Derechos, representación y la creciente calidad de la democracia en Brasil y Chile", Política y gobierno, v. 12, n. 1, p. 41-90.

HARDIN, R. 1999. "Do we want trust in government?" In: Warren, M. E. (Ed.). Democracy and trust. Cambridge: Cambridge University Press, pp. 22-41.

LAGOS, M. 2000. "A Máscara Sorridente da América Latina". Opinião Pública, Campinas, v. 6, n. 1, pp. 01-16. 
LEVINE, D. H.; MOLINA, J. E. 2007. "La Calidad de la Democracia en América Latina: Una Visión Comparada". America Latina Hoy, n. 45, 17-46.

MARAVALL, J. M. 2003. The Rule of Law as a Political Weapon. In: ; PRZEWORSKI, Adam (Orgs.). Democracy and the Rule of Law. Cambridge: Cambridge University Press, pp. 261-301.

MENEGUELLO, R. 2013. "As bases do apoio ao regime democrático no Brasil". In: Moisés, J. A.; Meneguello, R. (orgs.). A desconfiança política e os seus impactos na qualidade da democracia. São Paulo: EdUsp, pp. 52-93.

MOISÉS, J. Á. 2010a. "A corrupção afeta a qualidade da democracia?" Em Debate, Belo Horizonte, v.2, n.5, pp.27-37.

2005a. "A desconfiança nas instituições democráticas". Opinião Pública, Campinas, v. 11, n. 1 , pp. 33-63.

Disponivel em: $\quad$ http://www.scielo.br/scielo.php?script=sci arttext\&pid=S010462762005000100002\&lng=en\&nrm=iso. Acesso em: 31 jul. 2017.

. 2005b. "Cidadania, confiança e instituições democráticas". Lua Nova, São Paulo, n. 65, pp. 71-94. Disponível em: http://www.scielo.br/scielo.php?script=sci arttext\&pid=S010264452005000200004\&lng=en\&nrm=iso. Acesso em: 22 out. 2017.

- 2008. "Cultura política, instituições e democracia: lições da experiência brasileira" Revista brasileira de Ciências Sociais, São Paulo, v. 23, n. 66, pp. 11-43, fevereiro. Disponível em: http://www.scielo.br/scielo.php?script=sci arttext\&pid=S010269092008000100002\&lng=en\&nrm=iso. Acesso em: 26 set. 2017.

- 1995. Os brasileiros e a democracia: bases sócio políticas da legitimidade democrática. São Paulo: Editora Ática.

.2010b. "Os significados da democracia segundo os brasileiros". Opinião Pública, Campinas, v. 16, n. 2, pp. 269-309.

Disponível em: http://www.scielo.br/scielo.php?script=sci arttext\&pid=S010462762010000200001\&lng=en\&nrm=iso. Acesso em: 22 out. 2017.

MOISÉS, J. Á.; CARNEIRO, G. P. 2008. Democracia, desconfiança política e insatisfação com o regime: o caso do Brasil. Opinião Pública, Campinas, v. 14, n. 1, pp. 1-42.

Disponível em: http://www.scielo.br/scielo.php?script=sci arttext\&pid=S010462762008000100001\&lng=en\&nrm=iso. Acesso em: 22 out. 2017.

MOISÉS, J. Á.; MENEGUELLO, R. (org.). 2013. A Desconfiança Política e os seus Impactos na Qualidade da Democracia. 1ed. São Paulo: EDUSP - Editora da Universidade de São Paulo.

MORLINO, L. 2004. "What is a good democracy?" Democratization, v. 11, n. 5, pp. 10-32.

NORRIS, P. 1999. Critical citizens: global support for democratic governance. New York: Oxford University Press. 
SILVA, C. G. "Confiança política e qualidade da democracia: um debate teórico sobre o desempenho institucional"

O'DONNELL, G. 1998. “Accountability horizontal e novas poliarquias". Lua Nova, CEDEC, n. 44, pp. 27 - 54.

2010. Democracia, agencia y estado. Teoría con intención comparativa. Buenos Aires: Prometeo.

1991. "Democracia delegativa". Novos Estudos CEBRAP, São Paulo, v. 31, n. 92, pp.

$25-40$.

2001. "La irrenunciabilidad del estado de derecho". Revista Instituciones y Desarrollo, n. 8-9, pp. 43-82.

2002. "Las poliarquias y la (in)Enefectividad de la ley en América latina". In: Mendéz et. al. La (In)Efectividad de la Ley y la Exclusión en América Latina. Buenos Aires: Paidós, pp. 305-336.

2004. "Why the Rule of Law Matters". In: Diamond, L.; Morlino, L. (Ed). The Quality of Democracy: An Overview. Journal of Democracy, Washington, v. 15, n. 4, pp. 21-31.

OFFE, C. 1999. "How can we trust our fellow citizens?" In: Warren, M. E. (Ed.). Democracy and trust. Cambridge: Cambridge University Press, pp. 42-87.

SCHEDLER, A. 1999. "Conceptualizing accountability". In: SCHEDLER, Andreas; DIAMOND, Larry; PLATTNER, Marc F. (Ed.). Self-restraining State: power and accountability in new democracies. Boulder: Lynne Rienner Publishers, pp. 13-28.

WARREN, M. 1999. Democracy and trust. Cambridge: Cambridge University Press.

ZECHMEISTER, E. J.; LUPU, N.; COHEN, M. J. 2017a. "Democracy and Governance in the Americas: Key Findings from LAPOP's Americas Barometer". Latin American Public Opinion Project. Disponível em: https://www.vanderbilt.edu/lapop/insights/ITB030en.pdf. Acesso em: 07 out. 2017.

2017b. "The Political Culture of Democracy in the Americas 2016/17: A Comparative Study of Democracy and Governance". Latin American Public Opinion Project. Disponivel em: https://www.vanderbilt.edu/lapop/ab2016/AB201617 Comparative Report English V2 FINAL 090117 W.pdf. Acesso em: 07 out. 2017.

Tramitação do artigo na revista Submetido: 14/09/2018 Revisões requeridas: 03/02/2019 Versão revista: $27 / 02 / 2019$

Aceito: 07/03/2019 